\title{
ОСОБЕННОСТИ СТРАТЕГИИ ПРОДВИЖЕНИЯ ПРЕДПРИЯТИЙ ЛОГИСТИЧЕСКОЙ ОТРАСЛИ
}

\section{FEATURES OF THE PROMOTION STRATEGY OF THE LOGISTICS INDUSTRY ENTERPRISES}

\section{A. Kuzmicheva}

Summary. The article presents an analysis of the market of transport and logistics services in the Russian Federation, the scientific approaches to the definition of "market promotion strategy " are analyzed, the strategic analysis of the external and internal environment of the organization is carried out, the features of the strategy of "promotion to the market" of a transport and logistics enterprise are studied.

Keywords: strategy, market promotion strategy, transport and logistics company, SNW- analysis, analysis of the "Five forces of competition " by M. Porter, analysis of the key success factor (KSF), market of transport and logistics services.

\author{
Кузьмичева Алла Александровна \\ Доцент, ФГБОУ ВПО “Московский авиационный \\ институт" (Национально-исследовательский \\ университет) \\ allamai@list.ru
}

Аннотация. В статье представлена анализ рынка транспортно-логистических услуг (ТЛУ) в РФ, проанализированы научные подходы к определению "стратегия продвижения на рынок", проведен стратегический анализ внешней и внутренней среды организации, исследованы особенности проводимой стратегии "продвижения на рынок" транспортно-логистического предприятия.

Ключевые слова: стратегия, стратегии "продвижения на рынок", транспортно-логистическое предприятие, SNW-анализ, анализ "Пять сил конкуренции" по М. Портеру, анализ КФУ (ключевые факторы успеха), рынок транспортно-логистических услуг (ТЛУ).
$\Pi$ роцесс интеграции России в мировую экономическую систему сложен и долговременен. Тенденция развития национальной экономики РФ и наших ближайших соседей по СНГ заключается в том, что они становятся частью мирового экономического пространства. Налаживание мировых экономических связей невозможно без развития международной транспортной системы. Российская транспортная система является частью мировой. Ввиду этого ситуация на российском рынке транспортно-логистических услуг определяется динамикой экономического развития страны и оборота розничной торговли, темпы роста которых напрямую коррелируют с динамикой грузоперевозок. По причине прозрачности границ рынка ТЛУ (транспортно-логистических услуг) данный сегмент экономики РФ испытывает серьёзное влияние внешней ситуации. Замедление темпов роста грузоперевозок связано с ухудшением экспортной конъюнктуры на мировом рынке (оказывает влияние американо-китайская торговая война) и стагнацией внутреннего спроса в преддверии расширения антироссийских санкций. В рамках ежегодного исследования “Рынок логистического аутсорсинга. Итоги 2018-2019 и прогноз до 2022 г." специалисты агентства М. А. Research провели анализ текущей ситуации и перспектив развития мирового и российского рынка ТЛУ. По оценке M.A. Research, совокупный объем российского рынка ТЛУ в 2019 г. составит 3567 млрд. руб., номинальные темпы роста снизятся до 6,6\%.На российском логистическом рынке достаточно широко представлены многие крупнейшие мировые провайдеры. Укрепление их позиций связано с ростом масштабов деятельности западных розничных сетей и транснациональных компаний, ориентированных на широкое привлечение комплексных логистических услуг. Зарубежные логистические компании обладают огромным опытом в области организации транспортно-экспедиторской деятельности и являются сильными конкурентами для российских компаний. Несмотря на привлекательность российского рынка, объемы деятельности большинства западных логистических компаний внутри РФ еще не велики и не превышают $3 \%$ их оборота в масштабах мирового рынка [7]. Российский рынок транспортно-экспедиторских услуг находится на стадии роста и невелик в денежном выражении. Поскольку транспортная отрасль в РФ активно развивается, все компании ищут наиболее эффективные способы привлечения новых и удержания существующих потребителей. Логистические организации вынуждены вкладывать огромные средства в продвижение своего брэнда. Современная практика такова, что для продвижения логистических услуг активно используются различные виды, формы и каналы маркетинговых коммуникаций. Маркетинговые коммуникации на рынке "В-2-B" принципиально отличаются от коммуникаций на рынке "В-2-C", и очевидно, что для работы с клиентами - юридическими лицами нужно применять особые подходы. В случае неудачи рекламной кампании логистическое предприятие по- 
несет потери не только финансовые, оно рискует своим имиджем и позициями на рынке. Комплексные методы по продвижению логистической услуги потенциальным потребителям заключаются в следующем: использования рекламы на промышленном рынке, связей с логистической общественностью (PR), специальных методов стимулирования сбыта, личных продаж и т.п. Особенно важно информировать потребителя о характеристиках услуг и дополнительных возможностях. Важным моментом укрепления имиджа логистической компании становится публикации сведений о ней в специализированной прессе и отзывы других корпоративных клиентов. Транспортно-экспедиторские компании, поставившие цель расширение рынка, чаще всего используют стандартные рекламные средства: модули в специализированной прессе и Интернет - рекламу (банерную или контентную) [2]. Медиа - пространство тщательно подбирается, выбираются тематические медиа - ресурсы, но главный недостаток в том, что оказать воздействие на клиента невозможно, его можно только проинформировать. В ситуации высокой степени насыщенности рынка логистических услуг этого недостаточно, чтобы выиграть борьбу за потребителя.

В классических работах по стратегическому менеджменту устоялась точка зрения, согласно которой “стратегия продвижения на рынок" услуг базируется на обязательном проведении сегментации целевого рынка, выделении специфических групп клиентов, изучении индивидуальных потребностей, запросов и предпочтений потребителей целевой группы, их требований к элементам стратегического процесса, участниками которого они являются [1]. Другая точка зрения по данному вопросу заключается в том, что продвижение услуг это все формы деятельности компании, направленные на информирование, разъяснения, напоминания потенциальным потребителям о своих услугах [3]. При разработке "стратегии продвижения" организациям ТЛУ рекомендуется использовать следующие принципы: данная стратегия должна быть сконцентрирована на особенностях покупательского поведения потребителей услуг, необходимо определять целевую аудиторию и направленность рекламных сообщений, включать персонал во вторичную целевую аудиторию, подчеркивать интерактивное взаимодействие персонала и потребителя, влиять на мнение потребителей в сторону укрепления имиджа, подчеркивать преимущества трех «Р» логистической компании (процесса обслуживания, материальной среды и персонала) по сравнению с конкурентами [4]. Если удается соблюдать данное положение на практике, то клиенты почувствуют уникальность предлагаемой логистической услуги.

При проведении "стратегии продвижения на рынок" руководителям компании ТЛУ необходимо помнить о том, что для небольших организаций с ограниченным финансовым потенциалом конкурентная борьба за большой сегмент рынка может грозить разорением. Руководители должны отдавать себе отчет в том, что на рынке с большим количеством сильных игроков мелким логистическим организациям уготована роль аутсайдера. Альтернативной стратегией для таких компаний может стать ориентация на "узкую рыночною нишу", которая не интересна крупным игрокам. Нацелив специфику логистической услуги под потребность клиентов, фирма имеет все шансы стать одной из лучших в своём сегменте рынка.

Предметом данной статьи является определение особенностей "стратегии продвижения" логистической организации. Для изучения предмета были использованы методы социологического опроса, экспертных оценок, анализ первичных и вторичных документов. Была сформулирована и проверена гипотеза.

Логистическая компания работает на российском рынке ТЛУ с 2002года [6]. Согласно Уставу организация предоставляет своим клиентам следующие услуги: перевозки крупногабаритных и негабаритных грузов всеми видами транспорта в любую точку мира: морские перевозки, авиаперевозки, ж/д - перевозки, автоперевозки, контрактная логистика: складские услуги, дистрибуция, страховые услуги многое другое. В РФ были открыты пять офисов в четыре представительства компании в следующих регионах: Москва, Санкт-Петербург, Южно-Сахалинск, Мурманск, Сочи, Краснодар. Т.е. география размещения территориальных организаций обширна и охватывает почти всю Россию. Также компания арендует пять современных многофункциональных складских центров.

Стратегическое исследование стратегии логистического предприятия состояло из нескольких этапов. На первом этапе для изучения внутренней среды предприятия с точки зрения её влияния на характер стратегии было проведено интервью с директором по продажам и маркетингу компании. В ходе интервью было выявлено следующее: корпоративная стратегия, которой придерживается компания,- это стратегия развития, предполагающая расширение логистических услуг и пополнение кадрового состава для удовлетворения требований заказчиков. Директор говорит, что компания не использует организационный потенциал для реализации стратегии продвижения своих услуг. Комментируя слабые стороны организации, он отметил, что бренд компании не имеет достаточной известности в России. Работа отдела по продажам и маркетингу организована неправильно. Компания использует следующие маркетинговые мероприятия для реализации маркетинговой стратегии: связи с общественностью, стимулирование 
Таблица 1. Использование рекламы для продвижения услуг компании

\begin{tabular}{|l|l|}
\hline Варианты ответов & Удельный вес,\% \\
\hline Нет -50чел. & 100 \\
\hline итого & 100 \\
\hline
\end{tabular}

Таблица 2.- Эффективность программ стимулирования сбыта

\begin{tabular}{|l|l|}
\hline Варианты ответов & Удельный вес,\% \\
\hline Совершенно не эффективны & 26 \\
\hline Могли бы быть более эффективны & 62 \\
\hline Эффективны & 12 \\
\hline Итого & 100 \\
\hline
\end{tabular}

Таблица 3. Перечень основных сильных и слабых сторон организации

\begin{tabular}{|c|c|}
\hline Сильные стороны & Слабые стороны \\
\hline \multicolumn{2}{|c|}{ Функциональная зона управления «Персонал» } \\
\hline \multicolumn{2}{|l|}{ коммуникабельность } \\
\hline \multicolumn{2}{|l|}{ образование } \\
\hline \multicolumn{2}{|c|}{ Функциональная зона управления «Организация общего управления» } \\
\hline электронизация управления & - \\
\hline \multicolumn{2}{|c|}{ Функциональная зона управления «Маркетинг» } \\
\hline \multirow{4}{*}{ деловая репутация } & доля рынка \\
\hline & ценовая политика \\
\hline & Реклама \\
\hline & стимулирование сбыта \\
\hline \multicolumn{2}{|c|}{ Функциональная зона управления «Финансы» } \\
\hline- & Прибыльность \\
\hline
\end{tabular}

сбыта и прямой маркетинг. Компания не использует рекламу для продвижения своих услуг на рынке, а именно активное участие в ведущей международной выставке по транспорту и логистике «ТрансРоссия». Недостатком стратегии компании является ее англоязычный сайт. Компания занимает небольшую долю рынка, однако потенциал для роста в отрасли очень велик. В процессе экспертного опроса подтвердилась гипотеза: «Отсутствие рекламы приводит к тому, что потенциальные клиенты не проинформированы о возможностях компании».

Вторым шагом стратегического исследования стал анализ методом КФУ (ключевых факторов успеха) для определения сильных и слабых сторон логистической компании как ресурса проведения "стратегии продвижения" на рынок. Анализ был нацелен на внутреннюю среду и проводился по методу оценок стратегических ключевых факторов успеха организации (КФУ), влияющих на ее стратегический потенциал: персонал, организация общего управления, маркетинг и финансы. В ка- честве показателей, дефинициирующих основные КФУ, были выбраны следующие: КФУ «Персонал»: коммуникабельность, образование, уровень овладения специальным знанием. КФУ «Организация общего управления»: согласованность структуры и функции, электронизация управления. КФУ «Маркетинг»: деловая репутация, соотношение цены и качества, реклама, эффективность программ стимулирования сбыта. КФУ «Финансы»: рентабельность продаж. Для оценки значений показателей было проведен экспертный опрос. В исследовании приняло участие 50 человек, все - сотрудники компании, имеющих дело со стратегией по роду работы. Поскольку первые КФУ не имеют непосредственного отношения к стратегии, остановимся на факторе "реклама". Транспортно-экспедиторские компании используют рекламу, как для формирования долговременного образа организации, так и для распространения информации об услугах. Согласно полученным результатам экспертного опроса, логистическая компания не использует рекламу для продвижения своих услуг на рынке, см таблицу 1. 
Второй показатель, имеющий отношение к стратегии - это показатель «Эффективность программ стимулирования сбыта». Стимулирование сбыта включает в себя комплекс мероприятий по продвижению продаж. Компания проводит следующие мероприятия по стимулированию сбыта: участие в конференциях, банерная и контекстная рекламар. Согласно полученным результатам экспертного опроса программы стимулирования сбыта, которые проводит компания, могли бы быть более эффективны, таблица 2.

На основе полученных данных можно выделить основные сильные и слабые стороны компании ТЛУ.

В результате исследования внутренней среды компании подтвердилась гипотеза «Отсутствие рекламы приводит к тому, что потенциальные клиенты не проинформированы о возможностях компании».

Третьим шагом стратегического анализа явился отраслевой анализ методом "Пяти сил конкуренции по М. Портеру". Результаты исследования следующие:

1-я конкурентная сила - внутриотраслевая конкуренция. Данная сила характеризует интенсивность конкуренции среди действующих логистических компаний отрасли. На российском рынке ТЛУ действует множество мелких и средних транспортно-экспедиторских компаний, каждая из которых имеет незначительную долю рынка. Количество компаний, занимающихся грузоперевозками и транспортным экспедированием - около 4000. Все эти компании отличны друг от друга по спектру выполняемых операций, по типу обслуживаемых грузов, по опыту и профессиональному уровню и другим параметрам. Компании ТЛУ растут, расширяют спектр предоставляемых услуг и выходят в новые сегменты. На рынке усиливается как ценовая борьба, так и соперничество за счет улучшения качества услуг и расширения продуктовой линейки. Для компаний ТЛУ, уже завоевавших серьезные позиции на рынке и имеющих в своей клиентской базе крупных покупателей, ключевой задачей является удержание этих клиентов. 2-я конкурентная сила - возможность появления новых конкурентов. Новых конкурентов в отрасли транспортно-экспедиторских услуг привлекают: низкие барьеры на входе в отрасль, а также высокие темпы роста объема рынка. 3-я конкурентная сила - рыночная власть поставщиков. Власть поставщиков проявляется в их возможности влиять на потерю конкурентных позиций компаниями-потребителями, регулируя цены, качество, и возможности использования своей продукции или услуг. Изменения цен поставщиков или качества их продукции подействует на организацию в той мере, в которой она использует продукцию данного поставщика. Для транспортно-экспедиторских компаний наиболее значимыми поставщиками являются перевозчики - ави- акомпании, железнодорожные перевозчики, компании, осуществляющие контейнерные морские перевозки, автотранспортные предприятия. Перевозчики, являющиеся поставщиками транспортно-экспедиторских компаний, оказывают существенное влияние и на имидж компаний, на доверие со стороны клиентов. Основными поставщиками организации выступают:

1. В сегменте железнодорожных перевозок: ОАО «РЖД», Транспортная группа FESCO и ООО «Фирма «Рейл Сервис».

2. В сегменте автомобильных перевозок: ООО «Альфатрансгрупп», ООО «Совтрансавтоэкспедиция» и ICT Logistics A/S.

3. В сегменте авиаперевозок: Авиационная компания «Атлант-Союз», Амэрикэн Эйрлайнз Инк. и Авиакомпания ЭйрБриджКарго.

4. В сегменте морских перевозок: Мирасела Логистикс, ЗАО «Маэрск» и ЗАО «Контейнершипс Санкт-Петербург».

4-я конкурентная сила - рыночная власть потребителей.

Количество клиентов на бизнес - рынке намного меньше, чем на потребительском, а размер одной закупки, наоборот, значительно больше.

Конкурентная сила потребителей на рынке В2В сильна. Чем крупнее покупатели и чем большие объемы закупок они делают, тем больше они имеют возможностей влияния на ход переговоров с продавцом. Клиентами компании являются как крупные фирмы, которые постоянно пользуются услугами компании и приносящие большую часть прибыли, так и небольшие клиенты, осуществляющие разовые перевозки. На основании анализа клиентской базы договоров компании за 20182019 года были получены следующие результаты: доля российских компаний, составляет $45 \%$, оставшуюся часть (55\%) составляют международные компании, имеющие представительства в России или работающие с филиалами за рубежом.

5-я сила - потенциальные конкуренты для организации не существует.

Четвертым шагом стратегического анализа явилось исследование конкурентных преимуществ компании. Для определения конкурентной позиции компании был применен SNW-анализ. SNW-анализ (от англ. Strength, Neutral, Weakness) - это анализ сильных, нейтральных и слабых сторон организации. Результаты изложены в таблице.

Вывод по SNW-анализу: по не взвешенной оценке компания «ФМ Ложистик» обладает наибольшей кон- 
Таблица 4. Оценка конкурентоспособности компании

\begin{tabular}{|c|c|c|c|c|c|c|c|c|c|}
\hline \multirow[b]{2}{*}{ Ключевые факторы отрасли } & \multirow[b]{2}{*}{$\begin{array}{l}\text { Вес (для } \\
\text { взв.) }\end{array}$} & \multicolumn{2}{|c|}{ Кюн-Нагль } & \multicolumn{2}{|c|}{ Шенкер } & \multicolumn{2}{|c|}{ Панальпина } & \multicolumn{2}{|c|}{ ФМ Ложистик } \\
\hline & & H/B & B3B. & H/B & B3B. & H/B & B3B. & H/B & B3B. \\
\hline качество услуг & 0,3 & 5 & 1,5 & 4 & 1,2 & 5 & 1,5 & 4 & 1,2 \\
\hline географический охват & 0,1 & 2 & 0,2 & 4 & 0,4 & 3 & 0,3 & 4 & 0,4 \\
\hline благоприятный имидж & 0,1 & 4 & 0,4 & 4 & 0,4 & 4 & 0,4 & 3 & 0,3 \\
\hline комплексность услуг & 0,25 & 4 & 1 & 3 & 0,75 & 4 & 1 & 3 & 0,75 \\
\hline $\begin{array}{l}\text { наличие собственных складских } \\
\text { помещений }\end{array}$ & 0,05 & 1 & 0,05 & 3 & 0,15 & 1 & 0,05 & 5 & 0,25 \\
\hline $\begin{array}{l}\text { возможность отслеживания груза } \\
\text { через Интернет }\end{array}$ & 0,05 & 5 & 0,25 & 2 & 0,1 & 2 & 0,1 & 3 & 0,15 \\
\hline объективность стоимости услуг & 0,15 & 3 & 0,45 & 4 & 0,6 & 4 & 0,6 & 4 & 0,6 \\
\hline общая оценка & 1 & 24 & 3,85 & 24 & 3,6 & 23 & 3,95 & 26 & 3,65 \\
\hline
\end{tabular}

Таблица 5. Оценка конкурентной позиции компании

\begin{tabular}{|c|c|c|c|c|c|c|c|}
\hline \multirow{2}{*}{ Ключевые факторы отрасли } & \multicolumn{4}{|c|}{ Оценка конкурентной позиции конкурентов } & \multicolumn{3}{|c|}{$\begin{array}{l}\text { Оценка конкурентной позиции } \\
\text { организации }\end{array}$} \\
\hline & Шенкер & Панальпина & ФМ Ложистик & $\begin{array}{l}\text { Средний } \\
\text { бал }\end{array}$ & $S(=3)$ & $N(=2)$ & $W(=1)$ \\
\hline качество услуг & 1 & 2 & 1 & 1 & * & & \\
\hline географический охват & 3 & 3 & 3 & 3 & & & * \\
\hline $\begin{array}{l}\text { благоприятный имидж } \\
\text { компании }\end{array}$ & 2 & 2 & 1 & 2 & & * & \\
\hline комплексность услуг & 1 & 2 & 1 & 1 & * & & \\
\hline $\begin{array}{l}\text { наличие собственных } \\
\text { складских помещений }\end{array}$ & 3 & 2 & 3 & 3 & & & * \\
\hline $\begin{array}{l}\text { возможность отслеживания } \\
\text { груза через Интернет }\end{array}$ & 1 & 1 & 1 & 1 & * & & \\
\hline $\begin{array}{l}\text { объективность стоимости } \\
\text { услуг }\end{array}$ & 3 & 3 & 3 & 3 & & & * \\
\hline средняя оценка & 2 & 2 & 2 & 2 & & * & \\
\hline
\end{tabular}

курентоспособностью (общая оценка - 26 баллов); на 2-м месте - компании «Кюн-Нагль» и «Шенкер» (по 24 балла); компания «Панальпина» имеет наименьшую конкурентоспособность (23 балла).По взвешенной оценке наибольшей конкурентоспособностью обладает компания «Панальпина» (общая оценка 3,95 баллов), на 2-м месте компания «Кюн-Нагль» $(3,85$ балла), на 3-м - компания «ФМ Ложистик» (3,65 балла) и на 4-м компания «Шенкер» (3,6 балла).Наиболее точные результаты отражает метод по взвешенной оценке, т.к. учитывает значимость ключевых факторов отрасли для ее развития в целом и каждой кампании в отдельности. В этой связи конкурентная позиция компании «Кюн-Нагль» по отношению к группе основных ее конкурентов определяется методом SNW на основании взвешенной оценки в соответствии с таблицей 5.

Конкурентная позиция логистической организации совпадает с конкурентной позицией ее основных конку- рентов. Таким образом, компания имеет равные шансы с конкурентами на победу в конкурентной борьбе.

Пятым шагом стратегического анализа стал анализ стратегических альтернатив. Базовой корпоративной стратегией компании ТЛУ является "стратегия роста" (См. Интервью с директором). Данная стратегия предполагает постоянное повышение уровня показателей предыдущего периода. Альтернативной стратегией компании является "стратегия постоянных улучшений позиции на рынке". Стратегия "постоянных улучшений позиции на рынке" направлена на защиту и укрепление положения на освоенных рынках за счет увеличения объема продаж существующих продуктов. При реализации выбранной базовой стратегии "стратегия роста" возникают проблемы, которые будут препятствовать ее реализации, а именно отсутствие рекламы, недостаточное количество мероприятий по стимулированию сбыта, нехватка высококвалифицированного персонала в области маркетинга. 


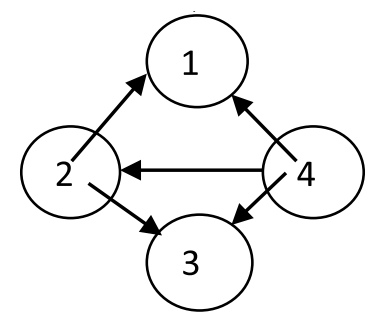

Рис. 1. Граф решения стратегических проблем

Для определения последовательности решения выявленных стратегических проблем строится граф решения стратегических проблем (рисунок 1):

Стратегические проблемы организации ТЛУ можно решить с помощью следующих функциональных стратегий: кадровая стратегия, финансовая стратегия, маркетинговая стратегия. Исследуя все виды стратегического анализа, можно однозначно отметить, что оптимальным вариантом для логистической компании может стать маркетинговая стратегия и её разновидность - "страте- гия продвижения на рынок" с учетом работы над выявленными слабыми сторонами организации.

В заключении можно отметить, что проведённое стратегическое исследования выявило следующий ряд проблем, существующих в компании и негативно влияющих на реализацию "стратегии продвижения" логистических услуг: основным фактором, тормозящим развитие, препятствующим расширению присутствия компании на российском рынке ТлУ, является не разработанная в деталях и не последовательно осуществляемая стратегия.

\section{ЛИТЕРАТУРА}

1. Котлер Ф. «Маркетинг менеджмент». 9-е международное издание, Спб: Питер, 1999, 325 с.

2. Пономарева Ю. Выставка, как способ продвижения на рынок логистических услуг. Журнал “Конъюнктура товарных рынков", 2008, № 4.c.6-8.

3. Портер М. Конкурентная стратегия: методика анализа отраслей и конкурентов.- М.: Альпина Бизнес Букс, 2005, 320 c.

4. Кузьмичева А. А. Влияние маркетингового потенциала на повышение конкурентоспособности инновационной организации. Транспортное дело в России. 2017.№ 1 (128). С.С.6-9.

5. Тультаев Т. А. Маркетинг услуг. Московская финансово-промышленная академия.—М., 2005, 97 с

6. Интернет источник www.kuhn-ngl.com.Дата обращения 25.04.2020

7. Официальный сайт «Складской портал» http://www.skladportal.ru/ Дата обращения 25.04.2020 